\title{
An Integrated Framework of Green Stormwater Infrastructure Planning-A Review
}

\author{
Gang Lu and Lin Wang *
}

check for updates

Citation: Lu, G.; Wang, L. An Integrated Framework of Green Stormwater Infrastructure Planning-A Review. Sustainability 2021, 13, 13942. https://doi.org/ $10.3390 /$ su132413942

Academic Editors: Alban Kuriqi and Luis Garrote

Received: 28 October 2021

Accepted: 6 December 2021

Published: 17 December 2021

Publisher's Note: MDPI stays neutral with regard to jurisdictional claims in published maps and institutional affiliations.

Copyright: (c) 2021 by the authors. Licensee MDPI, Basel, Switzerland. This article is an open access article distributed under the terms and conditions of the Creative Commons Attribution (CC BY) license (https:/ / creativecommons.org/licenses/by/ $4.0 /)$.
College of Environmental Science and Engineering, Ocean University of China, Qingdao 266100, China; lugang@stu.ouc.edu.cn

* Correspondence: lwang@ouc.edu.cn

\begin{abstract}
Conventional stormwater management infrastructures show low levels of sustainability owing to the consistent impact of urbanization and climate change, and the green stormwater infrastructure (GSI) has been identified as a more sustainable alternative approach. According to a systematic review, the articles and papers concerning GSI planning are fragmented, especially those discussing the planning steps; thus, an integrated framework of GSI planning is developed here to guide forthcoming planning. In the facility aspect, the research status and prospects of four critical planning steps (i.e., objective formulation, type/scenario evaluation, quantity/scale determination, and site selection) are discussed, and a method of quantifying the relationship between GSI and ecosystem services is given. In the ecosystem aspect, ecosystem resilience promotion is regarded as an approach to guarantee the interaction between hydrological processes and ecological processes, which maintains the sustainable provision of ecosystem services produced by GSI in diverse disturbances. Proposals for future GSI planning research are put forward as comprehensive consideration of the two abovementioned aspects to harvest ecosystem services from GSI directly and to promote the anti-disturbance ability of the ecosystem to guarantee the stable provision of ecosystem services indirectly, which are conducive to the social, economic, and environmental sustainability of GSI.
\end{abstract}

Keywords: green stormwater infrastructure; stormwater management; planning; eco-hydrology; ecosystem resilience

\section{Introduction}

In the past several decades, the appearance and functions of the urban environment have been altered tremendously by human behavior [1]. Urbanization leads to the expansion of cities and suburbs into rural areas and hence the fragmentation of natural resources [2]. Meanwhile, a series of environmental problems follow, e.g., the rapid expansion of impervious surfaces in urban areas, an increase in surface runoff, changes in soil conditions, a deterioration in water and air quality, and a negative impact on urban hydrological functions [1-4]. Moreover, urbanization intensifies human activities that directly affect the Earth's climate system through nonlinear processes [5], and climate change leads to a variety of precipitation patterns [6] and an increase in the frequency and intensity of storm events [7]. Under these circumstances, the feasibility of conventional stormwater infrastructures (e.g., gutters, tunnels, storm sewers, pipes, and channels) is reduced, because they are designed for transporting runoff to downstream areas as soon as possible [8] and may lead to insufficient groundwater recharge and the deterioration of water quality [1,9], although they minimize runoff accumulation and overflow problems. Urban floods are becoming more frequent [10-12], and the expansion of conventional infrastructures to cope with this problem has proven to be costly and unsustainable, especially in developed urban areas [13]. As a result, in the past century, stormwater management measures have gradually shifted focus from the rapid removal of rainfall from buildings and roads, without considering downstream effects, to minimizing impervious surfaces and adopting facilities that promote infiltration and evaporation [14]. As a more sustainable alternative 
approach, and differing from the conventional ones, green infrastructure (hereafter GI) focuses on decentralized units and the control of runoff near the source by imitating the natural hydrology and promoting the infiltration, evaporation, and retention of urban watersheds [15]. GI ensures that the hydrological conditions after development remain close to the natural conditions before development [3], which is conducive to returning runoff to the natural water cycle, groundwater recharge, reducing stormwater runoff, improving water quality, and reducing implementation and maintenance costs $[15,16]$. Since Prince George's County, Maryland, first pioneered GI in 1997, it has not yet been ascribed a precise and unified definition but instead has different definitions based on the actual research status and needs in respective fields. Among them, the definition given by the EPA [17] is cited most frequently: "a cost-effective, resilient approach to managing wet weather impacts that provides many community benefits ... ". To date, the research field of GI has focused on stormwater management and the common development of social and economic well-being, e.g., mental health, aesthetic value, and property improvement, for which the research has increased gradually. It has been pointed out that the ambiguity of the definition of GI has promoted its expansion in many fields, on the one hand, but, on the other hand, due to the scattered research and the irregular use of terms, the theoretical research and practical implementation of GI is hindered to a certain extent; therefore, this ambiguity is a double-edged sword [18].

Common consensus has been reached regarding GI on several grounds, the most important of which is that the function of GI is to provide multiple ecosystem services (hereafter, ESs) sustainably, with sustainability and multifunctionality. Scholars [18-20] integrated GI and ES to clarify their relationship. This paper is not dedicated to seeking a clear definition of GI but focuses on its planning and application in stormwater management; therefore, GI is regarded as an approach that provides various stormwater management ES, e.g., runoff reduction [21,22], water quality improvement [23,24], temperature regulation [25], biodiversity [26], habitat services [27], and aesthetic quality [28], and the most widely used types are green roofs, grassed swales, rain barrels, permeable pavements, bio-retention cells, and infiltration trenches. In recent years, ES has become the focus of decision-making processes to achieve sustainable development [29]. Urban stormwater management planning is one of the areas that strongly facilitates the integration of ES knowledge [30]. GI planning involves evaluating multiple ESs and also needs to reduce the complexity of the evaluation process and allow the comparison of different scenarios and the monitoring of implementation effects [31].

To emphasize the benefits of stormwater management, we use the green stormwater infrastructure (GSI) as the main term in this paper. At present, water quantity regulation and water quality regulation services for stormwater are the major objectives of GSI planning. Specifically, water quantity regulation services mainly include runoff volume reduction, peak flow reduction, and time-to-peak delay, while water quality regulation services are mainly the removal of TN, TP, COD, TSS, etc. Nevertheless, relevant GSI planning research involves disparate planning steps, e.g., Koc et al. [32] evaluate GSI scenarios to select the best one based on identifying the planning objective as runoff reduction; in contrast, Zhang et al. [33] directly assess the suitability of GSI construction without clearly setting out the planning objective, while Li et al. [34] put forward the planning objectives clearly as a $20 \%$ annual comprehensive runoff coefficient, evaluated the scenarios through SWMM and SUSTAIN, and calculated the construction area of GSI. Therefore, GSI planning may involve objective formulation, type/scenario evaluation, site selection, etc., which are given different considerations in different planning strategies. Even for the same step, such as objective formulation, a discrepancy in concrete methods exists; Koc et al. [32] simply describe the benefits of GSI in runoff reduction, without setting specific quantitative targets, while Li et al. [34] put forward the planning objectives quantitatively, as previously mentioned, and there are even some studies that do not mention the planning objective at all [35,36]. GSI planning is extensive and fragmented, without standard planning steps or methods, which limits its development. Moreover, 
given that GSI is a concept of ecological planning, researchers have realized that the success of GSI planning depends on the facilities themselves, but it is also restricted by the ecosystem. A system with high resilience can absorb changes and remain in the same state in a series of disturbances and management actions; on the contrary, one with low resilience may react strongly and move to another state [37], so different ecosystem states may lead to differences in the performance of the GSI system, and even failure. A feasible solution is to promote ecosystem resilience through optimization measures, so as to ensure the stable operation and interaction of ecological processes and hydrological processes, and indirectly promote the sustainable provision of ESs [38,39].

In accordance with the review of existing studies, we found that GSI planning research is extensive and fragmented, and there is still a lack of detailed instructions for the GSI planning steps; in addition, there is no review of GSI planning that integrates the facility aspect and ecosystem aspect simultaneously. Therefore, the objectives of this paper are to (1) review and synthesize the published literature and identify the research gaps, and (2) make suggestions for future GSI planning to harvest stormwater management ES in terms of both facility and ecosystem, which will aid planners and managers in managing stormwater sustainably.

\section{Methods}

We searched the related literature via Web of Science, and the results showed that GSI research involves multiple terms (i.e., green infrastructure, green stormwater infrastructure, low-impact development, best management practice, ecosystem services, water-sensitive urban design, sustainable urban drainage system, sponge city, ecosystem resilience, greenway, greenbelt, and ecological infrastructure). In fact, these terms are similar and interchangeable in most cases, without clear separation. For the convenience of research, this review used GSI as an alternative. We searched all the terms and checked the abstracts of the papers that contributed to this review. A total of 158 papers were reviewed, 67 of which were searched and checked with the terms and planning as keywords. We summarized the four critical steps of GSI planning through the abovementioned 67 planning articles, i.e., objective formulation, type/scenario evaluation, quantity/scale determination, and site selection, which were considered frequently. It should be noted that a list of the 67 consulted articles is provided in the Supplementary Materials. Furthermore, we calculated statistics for the planning steps considered in these planning articles to illustrate the current situation of GSI planning, which are discussed in Sections 3 and 4. The other 91 papers were consulted to illustrate the effect of ecosystem resilience promotion on GSI planning, and we discussed the approaches to promoting ecosystem resilience; some experiment or review papers were also taken into consideration, such as the evaluation of GSI performance to indicate the ES that it may provide, which helped us to understand the topic more comprehensively.

In fact, the review of this literature was only a starting point, through which we proposed an integrated framework (Figure 1) for GSI planning to discuss possible research directions for future GSI planning in terms of both facility and ecosystem to improve sustainability. Regarding the facility aspect, four key steps of GSI planning were summarized based on the published literature, and the possible directions for future research were discussed based on the analysis of the current research status of each step. In order to obtain the stormwater management ES from the GSI facilities directly and efficiently, we discussed how to formulate the objectives, how to evaluate the GSI types/scenarios, how to determine the quantity/scale, and how to select the sites. Regarding the ecosystem aspect, we analyzed the benefits of ecosystem resilience promotion to the ES based on the literature and put forward the research directions of future GSI planning in terms of promoting ecosystem resilience, which contributes to strengthening the stable interaction between ecological and hydrological processes, and ensures that the GSI system can still operate in response to disturbances with the sustainable supply of ES. This integrated framework can provide a reference for GSI planners and stakeholders. 


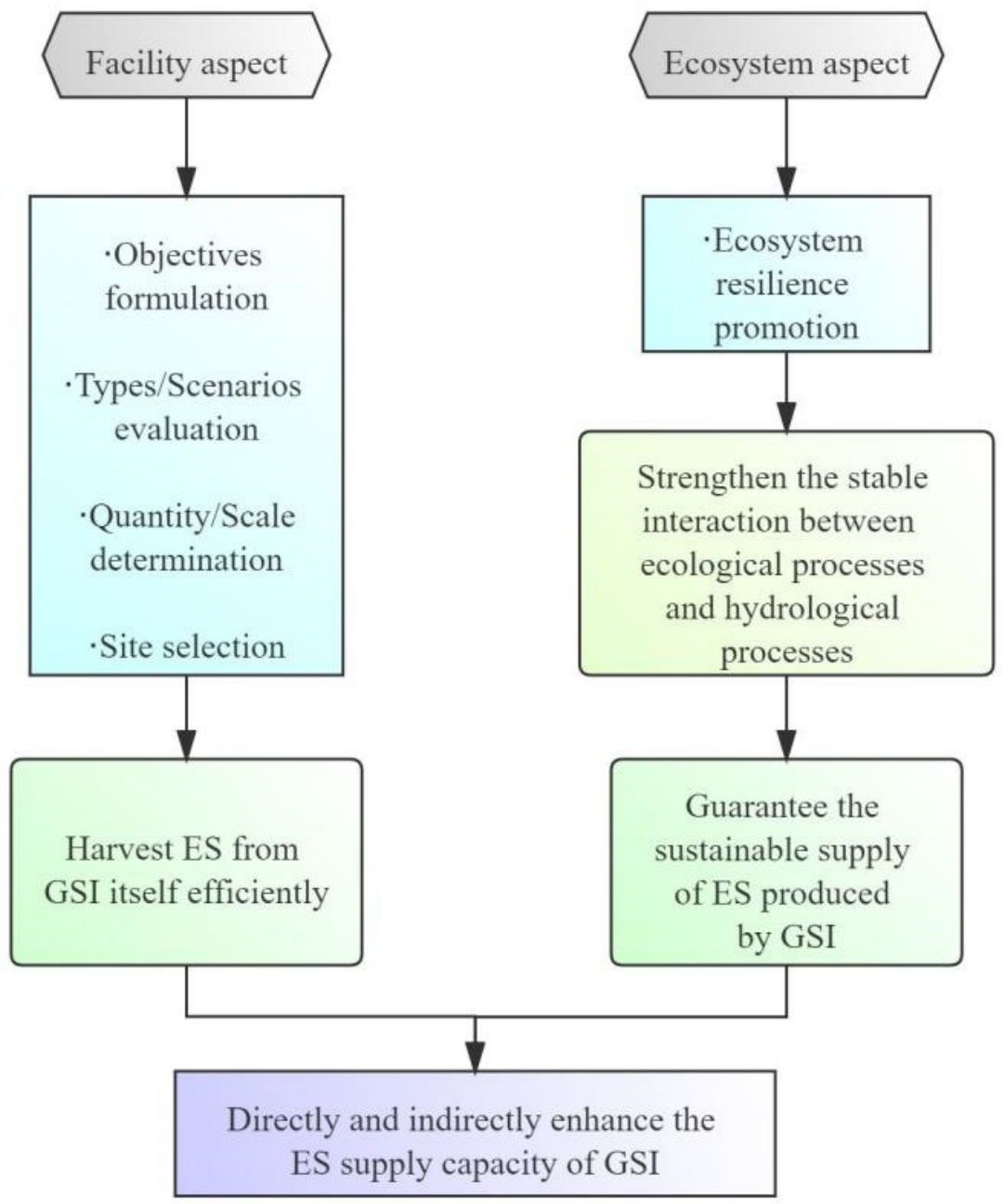

Figure 1. The GSI planning framework.

\section{Results}

\subsection{Overview of the Planning Articles Reviewed}

Among the 67 planning articles reviewed, the number of articles that contained objective formulation, type/scenario evaluation, quantity/scale determination, and site selection is $60,58,14$, and 20 . It is known that objective formulation and type/scenario evaluation are the hotspots of GSI planning at present, while the planning approaches that considered quantity/scale determination or site selection are less than one-third of the articles. In addition, there were only 3 articles that contain all planning steps, and 16 articles with consideration of 3 steps, while most (43) articles included 2 steps, 33 of which dealt with the objective formulation and the type/scenario evaluation. The remaining five articles only carried out a single step. Therefore, the current GSI planning is fragmented and the planning steps considered are not consistent and comprehensive in articles, which may limit the development of GSI planning and construction. It is therefore insightful to identify the research gaps of the planning steps from the facility perspective. A detailed description of the distribution of planning steps considered in these articles, and a detailed discussion of each planning step, are carried out in Sections 3.2-3.5.

\subsection{Objective Formulation}

Among the selected 67 planning-related articles, there were 60 studies that contained objective formulations, which mainly addressed water quantity regulation services (e.g., runoff volume reduction, peak flow reduction, and combined sewer overflow) and water quality regulation services (i.e., the removal of runoff pollutant), as well as referring 
to greenhouse gas emissions (1), temperature regulation (3), biodiversity enhancement (5), cultural services (2), and social and economic benefits (5). The planning objectives were formulated as one or more of the abovementioned ES, and 56 articles $(93 \%)$ formulated their objectives as the water quantity regulation or water quality regulation services; these two types of ES are still the dominant objectives of GSI planning. Only 3 articles put forward clear quantitative objectives, and the other 57 articles briefly summarized the planning goals in a qualitative way based on the functions confirmed by the relevant research of GSI. Another 7 studies did not mention the concept of planning objectives and directly proceeded to other steps in planning. This may be attributed to the fact that the authors utilized the relevant functions of GSI that were widely confirmed, and therefore, there was no need to specifically propose the objective. Current planning objectives lack quantitative and precise considerations, which may be caused by two reasons: Firstly, researchers are accustomed to directly providing qualitative planning objectives that may be feasible in explaining the functions of GSI. However, the ambiguous expression of such objectives may induce a decrease in the interest of investors and stakeholders, thus hindering the development of GSI. Secondly, the quantitative research on the function of GSI is still immature. For example, in the literature review, as regards the runoff volume reduction using strategies such as bioretention (BR), green roof (GR), infiltration trench (IT), permeable pavement (PP), rain barrel (RB), and vegetative swales (VS), the research results show high spatial heterogeneity, as shown in Table 1.

Table 1. Runoff volume reduction, implementation cost, and annual maintenance costs of six types of GSI.

\begin{tabular}{|c|c|c|c|c|}
\hline & Main Function & $\begin{array}{c}\text { Runoff Reduction } \\
\text { Rate (\%) }\end{array}$ & $\begin{array}{l}\text { Implementation Cost } \\
\left(\mathrm{USD} / \mathrm{m}^{2}\right)[40]\end{array}$ & $\begin{array}{l}\text { Annual Maintenance } \\
\text { Cost }\left(\mathrm{USD} / \mathrm{m}^{2}\right)[40]\end{array}$ \\
\hline Bioretention (BR) & $\begin{array}{l}\text { Infiltration } \\
\text { Retention } \\
\text { Purification }\end{array}$ & $\begin{array}{c}50[41] \\
>60[42]\end{array}$ & $109-227$ & 6 \\
\hline Green roof (GR) & Retention & $\begin{array}{l}77.2[43] \\
62.2[44]\end{array}$ & $\begin{array}{c}\text { Extensive: } 112 ; \\
\text { Semi-intensive: } 147 ; \\
\text { Intensive: } 409\end{array}$ & $\begin{array}{c}\text { Extensive: } 4.84 ; \\
\text { Semi-intensive: } 8.78 \text {; } \\
\text { Intensive: } 6.37\end{array}$ \\
\hline Infiltration trench (IT) & Infiltration & $\begin{array}{l}33-61[45] \\
16-70[46]\end{array}$ & 97-149 & 4.54 \\
\hline Permeable pavement (PP) & Infiltration & $\begin{array}{c}43[47] \\
4.2-10.5[48] \\
80[49]\end{array}$ & $53-81$ & 0.91 \\
\hline Rain barrel (RB) & Retention & $\begin{array}{c}7.4[50] \\
18-40[51] \\
2-12[52]\end{array}$ & 1.91 & 0.02 \\
\hline Vegetative swale (VS) & $\begin{array}{l}\text { Transportation } \\
\text { Infiltration }\end{array}$ & $\begin{array}{c}17[53] \\
5.11-13.46[54] \\
40-75[55]\end{array}$ & 0.20 & 0.01 \\
\hline
\end{tabular}

Since a quantitative relationship between GSI and ES cannot be clearly known, it is formidable to determine an appropriate clear objective based on existing studies or to determine whether the GSI planning objective can be achieved after it is formulated quantitatively. Moreover, based on the literature review regarding water quality regulation, the initial conditions (e.g., climate, geology, and the composition and number of pollutants in stormwater runoff) of different study areas are inconsistent, which makes even a certain type of GSI show different water quality regulation capabilities, as shown in Table 2. Researchers adopt a variety of facility configurations in actual operations, such as filler and plants. Furthermore, GSI planning is increasingly inclined to address a combination of different types of facilities, which makes objective formulation more complicated. 
Table 2. The runoff reduction and pollutant removal performances of bioretention.

\begin{tabular}{|c|c|c|c|}
\hline Function & Performance (\%) & Reference & Location \\
\hline \multirow[t]{4}{*}{ Runoff reduction } & 50 & {$[41]$} & Cincinnati, USA \\
\hline & $>60$ & [42] & Kyoto, Japan \\
\hline & $16.1-99.8$ & [56] & Nanning, China \\
\hline & 75 & [57] & Guangzhou, China \\
\hline \multirow[t]{4}{*}{ Pollutant removal } & $\begin{array}{l}\text { COD: } 94.6 \text {; } \\
\text { TP: } 93.7\end{array}$ & [58] & Xian, China \\
\hline & $\begin{array}{c}\mathrm{NO}^{-}{ }_{3}-\mathrm{N}: 73.8-100 \\
\text { Ammonium: 80.5-97.4 }\end{array}$ & [59] & Beijing, China \\
\hline & $\begin{array}{c}\text { Nitrate nitrogen: 70-90; } \\
\text { TN: 75-90; } \\
\text { TN: 90; } \\
\text { ammonia nitrogen: 80; } \\
\text { COD: } 25-50\end{array}$ & {$[60]$} & Xian, China \\
\hline & $\begin{array}{c}\text { TSS: } 94 ; \\
\text { Ammonia: } 85 ; \\
\text { total copper: } 59 ; \\
\text { total zinc: } 80\end{array}$ & [61] & Potland, USA \\
\hline
\end{tabular}

\subsection{Type/Scenario Evaluation}

Among the reviewed articles, there were 58 articles that addressed GSI type or scenario, 23 studies of which are directly based on local conditions and existing research results of GSI facility types for selecting one or more type(s) of GSI, while the other 35 articles are based on a number of preliminary alternatives from which the best solution is selected by evaluating multiple criteria. We do not deny the efforts of the former in terms of research caliber but endorse the reliability of the latter for reducing the weight of subjective judgments in decision making. When considering the infiltration function, for example, BR, IT, and PP may all be appropriate choices, if a solution is directly determined by a planner or institution; thus, strong subjective factors may be inevitable. The type/scenario evaluation process incorporates criteria from multiple dimensions of society, economy, and environment comprehensively, which makes the corresponding GSI planning more likely to be adopted and implemented. In addition, the evaluation of multiple alternatives is also in line with the trend in GSI planning of choosing combined facilities, as it can help to distinguish the functional differences between diverse facility types themselves and their combinations, and to broaden the research field of GSI. Hua et al. [62] simulated the two-dimensional runoff routing processes under different GSI scenarios and storm patterns via a hydrological model; they used an evaluation system consisting of life cycle cost analysis, analytic hierarchy process, and regret decision theory, the criteria of which covered technology, economy, environment, and operational aspects; lastly, the best strategy was determined as the combined use of bioretention, infiltration trenches, and rain barrels. Similarly, Kourtis et al. [63] proposed a framework for evaluating stormwater management measures in urban basins; they included hydrological, hydraulic, and economic criteria, aiming to quantify the impact of alternatives on mitigating urban flood, and evaluated the construction, operation, and maintenance costs of all scenarios based on a typical life cycle (30 years). Comparing the conventional scheme (offline detention tanks, sewer enlargement) and GSI (GR, PP) with no stormwater management measures, the results showed that the GSI solution performed more effectively when traffic congestion, noise, construction difficulty, and the impacts of coordination downstream are taken into comprehensive consideration. Accurate quantities of ES provided by GSI cannot be obtained currently; therefore, the values of evaluation criteria of water quality and quantity regulation services are not accurate enough. Consequently, the credibility of the best type/scenario through 
this evaluation is still low, and therefore, it is urgent to quantitatively identify the values of ES provided by GSI.

\subsection{Quantity/Scale Determination}

Among the 67 planning studies reviewed, only 14 included the step of quantity/scale determination. However, most of these studies simply designated the areas where GSI, entirely or in part, can be built as planned areas; thus, the selected quantity or scale was not calculated and evaluated in detail, which means large randomness and subjectivity. In these articles, providing enough expected ES cannot be guaranteed, and the interest of stakeholders cannot be enhanced by minimizing GSI investment either. There are also studies that made efforts to attain the quantity or scale via calculation or evaluation. Men et al. [64] combined and optimized the SWMM model by using the preference-inspired co-evolutionary algorithm using goal vectors (PICEA g) in accordance with the maximum buildable area of $\mathrm{PP}$, and GR, compared with the study area, and calculated the optimal construction areas of GSI regarding four objectives, i.e., total runoff reduction, peak flow reduction, the removal of suspended solids (SS), and total cost. Guerrero et al. [21] constructed a decision-support system to simulate the runoff volume reduction performance of different construction areas with porous concrete pavement, bioretention, and bioswales, which can be used to determine the construction areas of GSI according to the objective of runoff volume control. It is worth noting that most of these quantitative studies refer to the relevant GSI water quality and quantity regulation capabilities given by existing studies, such as the runoff coefficient of various types of facilities [34], or the default GSI performance that is calculated by parameter settings with large uncertainties in the hydrological model $[64,65]$. A method supporting the idea that GSI can provide the same amount of ES in different planning scenarios is bound to be flawed, as the discussion regarding performance discrepancy in different studies in Sections 3.2 and 3.3 revealed. Fundamentally speaking, a considerable amount of uncertainty between GSI and ES results in these shortcomings. On the one hand, the ambiguity of the number of ES that GSI can provide leads to the ambiguity of objective formulation, which makes the quantity/scale determination lack accurate objective constraints. On the other hand, even if a certain quantitative objective is given, the planning is still subject to uncertainty and unable to determine the precise quantity or scale. An increasing number of studies $[20,66]$ point to a consensus that the function of GSI is ES production, and they agree that it is necessary to quantify the relationship between the two, as they believe quantification will help incorporate GSI into relevant environmental policies more widely and enhance the interest of stakeholders, so as to understand and implement effective GSI practices; however, they have not achieved breakthrough results yet.

\subsection{Site Selection}

Among the 67 reviewed articles, 20 articles included the criterion of site selection. The location of GSI is often regarded as a significant factor affecting the effectiveness of planning [67]. Therefore, identifying high-priority construction areas for various GSI types is always a research hotspot. The appropriate sites contribute to the reduction in the vulnerability of the study area (e.g., floods, climate change), and the acceleration of the production of a wider range of ES [68]. Taylor et al. [69] integrated GIS with e-tools, and identified the potential GSI areas based on the determination of the existing GSI, and the principles of its site selection were as follows: vegetation height $<1.5 \mathrm{~m} ; 10 \mathrm{~m}$ buffer zone for cemeteries, playgrounds, and railways; exclusion of impervious surface areas, golf courses, historical sites, water bodies, and wetlands; polygons $\geq 9.29 \mathrm{~m}^{2}$. MartinMikle et al. [70] identified hydrologically sensitive areas by extracting land-use types to calculate the topographic index and selected 140 priority GSI sites after the identification of land use, spatial scale, and the applicability of constructing GSI in impervious areas. Li et al. [71] evaluated priority sites for GSI to mitigate floods in Ghent, Belgium, through runoff coefficient, socially sensitive groups, road sensitivity, building sensitivity, and 
environmental justice. Langemeyer et al. [72] discussed six types of ESs, i.e., heat regulation, runoff control, habitat, food production, entertainment and leisure, and social cohesion through multi-criteria decision analysis (MCDA) to select priority areas for green roofs in Barcelona, while Song et al. [73] selected eight criteria in three dimensions-social, hydrologic, and physical-geometric - to construct the MCDA framework to evaluate the performance of infiltration trench and permeable pavement in eight sub-catchments in Seoul, South Korea, then ascertained the best location.

\section{Discussion}

\subsection{Facility Aspect}

4.1.1. Objective Formulation

We affirm the significance of objective formulation, as it affects all subsequent planning steps. If the objective is always described qualitatively, not only will the interest of stakeholders and investors become lower and lower, it will also lead to loopholes in all subsequent planning steps (i.e., type/scenario evaluation, quantity/scale determination, and site selection) and considerable hidden dangers. A feasible solution is according to the ES (i.e., water quantity regulation and water quality regulation services in this review) that GSI can provide, and building an integrated framework of GSI and ES to fully identify the functions of GSI, so as to accomplish the multifunctionality of GSI to obtain maximum benefits. However, the ES concept is rarely used explicitly in planning objectives, which may be caused by the fact that it is not clear how ES provides guidance for decision-making information and whether ES concepts should be introduced in the objective formulation step [74,75], while others argue that the ES concept is not clear enough among planning practitioners and has not reached a broad understanding [76,77]. In fact, urban stormwater management planning is one of the areas that strongly facilitates the integration of ES knowledge [66], and GSI planning affects ES in multiple ways at different decision-making levels [78]. Future GSI planning needs to reduce the complexity of the evaluation process to attract more stakeholders' attention to understand the ES concept. ES assessment has been increasingly conducted as an imperative source of knowledge to support decision making [79]. Meanwhile, incorporating ES assessment results into decision-making processes usually means a significant increase in the amount of information that needs to be considered [80]. In complex decision-making problems, proper knowledge synthesis is a basic step to reduce the burden of information and support evidence-based decision making. Therefore, how to effectively integrate multiple ES assessments is a problem that needs to be solved in the objective formulation step in future GSI planning [66], which means the trade-off among ES should be taken into account, e.g., increase in aquifer storage and groundwater pollution, water purification, and water flow temperature management [20].

In addition, similar or different GSI facility types in different studies perform different functions, which impedes a quantitative objective formulation, as shown in Tables 1 and 2. A viable method is that the authorities summarize various water quantity and water quality regulation capacities of different GSI facility types based on as many existing studies as possible, taking the spatial heterogeneity into account, and then formulate reference values, with reasonable ranges that are based on social, economic, and environmental conditions of specific study areas, which may be more suitable than fixed values, as the latter may affect the rationality of planning objectives. Xu et al. [81] set the water quantity regulation objective according to the Urban Flood Control Engineering Disciplines, China (GB/T50805-2012), while the water quality regulation objective was set based on the water quality volume criterion of BMPs developed by the US Environmental Protection Agency (USEPA); nevertheless, the planning area was Shanghai, China. This method of randomly setting objectives with reference to different standards is obviously flawed. Reference standards should consider regional differences, and provide the best reference range for water quantity and quality regulation objectives such as pollutant reduction rate and total runoff control rate; for example, Zheng et al. [44] integrated 75 GR studies and quantified the average runoff retention rate that reached $62.2 \%$. There are already authori- 
tative references-the USEPA has set an objective for retaining the 95th percentile rainfall event [82]; China's Technical Guide for Sponge City Construction (Trial) [83] proposed $70-90 \%$ annual runoff control rate targets for different regions, which sets different runoff control objectives for different subareas and is in line with real-world scenarios to guide the objective formulation in planning areas with different conditions. In line with Roggero [84], highlighting the benefits of policy instruments for GSI planning, these policies have leading roles in planning. However, as shown in the literature we reviewed, there is no clear quantitative objective reference for water quality control or other aspects of water quantity control, and studies only qualitatively proposed factors such as pollutant removal, runoff peak reduction, and time-to-peak delay, without accurate values. Moreover, as relevant studies are increasingly inclined to investigate comprehensive GSI scenarios with multiple facility type combinations, the synergy of facilities in the future should also be taken into consideration.

\subsubsection{Type/Scenario Evaluation}

The type/scenario evaluation should set up preliminary, optional GSI scenarios based on the actual situation of planning areas after determining the ES requirements during the objective formulation step. These options may involve a combination of various types of GSI, where the opinions of experts who are familiar with related fields and planning areas are instrumental. The key to this planning step lies in the selection of evaluation criteria and their weight determination. The evaluation involves multiple dimensions, so the adopted and feasible approach is to build frameworks of MCDA [32,62,85] to integrate the selected criteria and their weights for evaluating the performance of the GSI types or scenarios and determining the best one. As an alternative to conventional methods, GSI makes up for their low level of sustainability [10], and the entire life cycle of GSI, i.e., planning, implementation, operation, and maintenance, is related to multiple dimensions of society, economy, and environment; thus, we recommend that the criteria system of evaluation frameworks should cover the three dimensions of social sustainability, economic sustainability, and environmental sustainability, so that the most favorable option for the comprehensive sustainability encompassing the above three dimensions can be identified, which is feasible and advantageous. Based on the reviewed articles, we enumerate reference evaluation criteria (Table 3) for social sustainability, economic sustainability, and environmental sustainability, which can provide guidance for related planning. Actual planning may assign the criteria subjectively and objectively; for example, the environmental and operational criteria in the planning of Hua et al. [62] are assigned by subjective judgments of the authors, while other indicators are assigned through simulation or calculation, which does not mean that these values are accurate enough. When assigning ES criteria in the evaluation system, the inability to accurately quantify the relationship between GSI and ES reduces its accuracy, which is similar to the defects pointed out in the step of objectives formulation and also emphasizes the urgency of quantifying the relationship between GSI and ES.

Table 3. Example criteria to evaluate the social, economic, and environmental sustainability of the alternative scenarios.

\begin{tabular}{ccc}
\hline Social & Economic & Environmental \\
\hline Aesthetic & Initial investment cost & Runoff volume reduction \\
Community resistance & Operational cost & Punoff reduction \\
Employment probability & Operational feasibility & Time-to-peak delay \\
Social acceptability & Implementation cost & Removal of TSS, COD, TN, TP, etc. \\
& Maintenance cost & Annual runoff volume control \\
& & Runoff duration time \\
& & Impact on flora and fauna \\
& Greenhouse gas emission & Groundwater recharge \\
& Rainwater usage
\end{tabular}


As regards the determination of criteria weights, analytical hierarchy process (AHP) or AHP-based integrated methods are often used $[32,62,85]$, which have been widely utilized to evaluate decision criteria for various topics [86]. AHP is a simple tool for MCDA but with a certain degree of subjectivity. Conventional AHP cannot provide decision making for uncertain issues based on subjective judgment; therefore, scholars have made some efforts to remedy this, such as using improved AHP to cope with the subjectivity inherent in human judgment $[32,85]$. In addition, the decision of the type/scenario evaluation still needs to be verified to ensure that it can be conducted in practice, which means the options should be verified through case studies and communication with decision makers in the future.

\subsubsection{Quantity/Scale Determination}

In order to make up for the existing shortcomings, it is essential to analyze the mechanism of how GSI provides ES. The dominant features covered in this review are water quantity regulation and water quality regulation ESs that GSI provides by making full use of natural elements, especially vegetation (e.g., BR, GR, VS), to carry out stormwater infiltration, retention, transmission, evapotranspiration, and purification processes; this is exactly the essential difference between GSI and conventional methods; in other words, GSI planning can introduce ecological processes (mainly related to vegetation), and as there are complex interactions between ecological and hydrological processes, changes in hydrological processes will occur, thus the production of various ESs such as water quantity and quality regulation. There are mutual influences (Figure 2) between ecological and hydrological processes. On the one hand, the evapotranspiration process of vegetation transports water to the atmosphere; the growth of vegetation roots affects the structure of soil porosity, thereby changing the distribution of surface and deep soil moisture [87]; the existence of rhizosphere microorganisms and vegetation absorption facilitates the removal of heavy metals, nitrogen, phosphorus, bacteria and other pollutants in the water body; the increase in vegetation cover with the canopy interception contributes to the redistribution of precipitation; compared with other land cover types, vegetation cover generally has a lower runoff coefficient, which helps reduce the peak runoff and delay the peak time [88]. Conversely, hydrological elements, such as flow volume, flow velocity, water quality, and water level, affect the structure, dynamics, distribution, and succession of vegetation communities; hydrological processes such as infiltration, abortion, and confluence affect the flow of nutrients, pollutants, minerals, and organic matter in the ecosystem and its distribution in soil and water bodies; moreover, hydrological processes contribute to improving hydrological connectivity, recharging watershed water volume, making hydrological gradients smoother at the large scale (e.g., watershed and country), and the integrity of ecosystems [89]. The water cycle takes the atmosphere, vegetation, and soil as basic media for the migration and conversion of water, while the material circulation and energy flow of the ecosystem driven by the water cycle maintain its critical structure and function.

There are many differences in hydrological, ecological, and other features of society, economy, and environment among the study areas, so different responses between hydrological and ecological processes are bound to be involved, which leads to different performances of GSI. The above-mentioned idea of referring to the default values given by existing research or hydrological models $[70,90,91]$ is still dedicated to obtaining the direct quantitative relationship between GSI and ES, which ignores the discrepancy of the hydrological and ecological process responses in different planning scenarios, and it should be amended. We suggest an indirect method to determine the quantity or scale, i.e., exploring the interaction mechanism between local hydrological and ecological processes in each planning area, then identifying the response and variation of hydrological processes driven by the ecological processes that are introduced by GSI, so as to determine the extent of ESs that these responses and variations can produce, as shown in Figure 3. We are not committed to obtaining a simple quantitative relationship between GSI and ES once and 
for all, proven to be unattainable, but to provide an indirect quantitative approach that can be used for the future GSI planning step of quantity/scale determination, where the identification of the interaction mechanisms between local hydrological and ecological processes in each planning is encouraged.

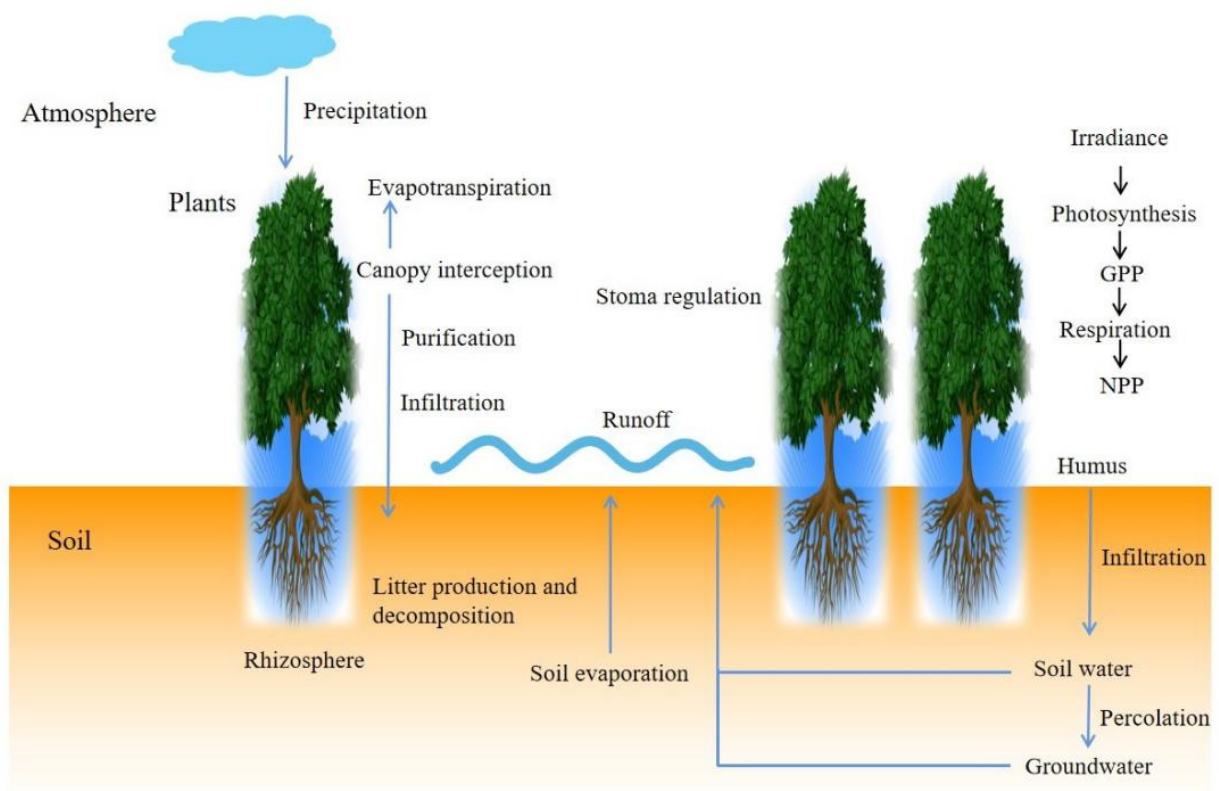

Figure 2. The interaction between hydrological processes and ecological processes [80-82].

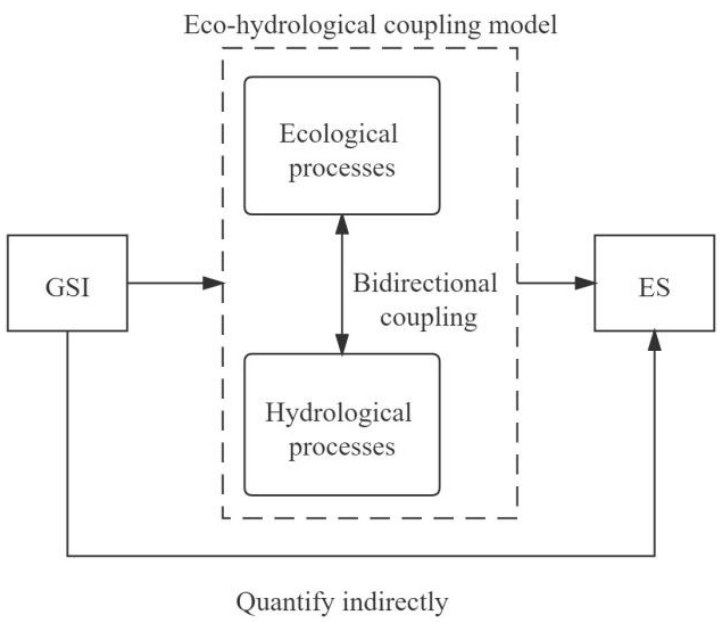

Figure 3. The method of quantifying the relationship between GSI and ES by eco-hydrological coupling model.

The eco-hydrology proposed by the United Nations Conference on Water and Environment [92] in 1992 provides an understanding of the complex interaction between hydrology and ecological processes quantitatively. The method that has been adopted is to construct a coupling model of hydrology and ecology, where the two-way feedback of hydrological and ecological processes can proceed. Specifically, numerous variables and parameters in hydrological and ecological models are used to simulate the hydrological and ecological processes, and the variables and parameters that exist in the two types of models at the same time support the feedback. Related research on the coupling of these two systems has been extensively carried out. Marshall et al. [93] applied the Simultaneous Heat and Water (SHAW) model, loosely coupled with the Geophysical 
Institute Permafrost Laboratory (GIPL) model to simulate the soil moisture dynamics. Cristiano et al. [94] used an eco-hydrological streamflow model for urban areas (EHSMu), taking into consideration water and soil dynamics, vegetation types, evapotranspiration fluxes, and aquifer recharge, and simulated the runoff formation, evapotranspiration, and aquifer recharge on an hourly scale. These studies are helpful to analyze the migration of water in the soil-plant-atmosphere continuum (SPAC) [95]. Under the drastic process of climate change and urbanization, it is inevitable to consider climatic and social disturbance factors. Yu et al. [96] coupled the vegetation interface processes (VIP) model with the China AgroSys model to simulate eco-hydrological processes, such as crop yield, evapotranspiration, and runoff yield, and discussed the human impact on hydrology and ecology within the basin and region. Li et al. [97] coupled an eco-hydrological model (GBEHM-HEIFLOW) with a socio-economic model (WEM-HRB), taking into account the impact of the socioeconomic system, and developed a watershed system to simulate the coevolution of natural and social systems with water-land-air-plant-human nexus. Among the coupling models, there are differences in the degree of simplification of eco-hydrological processes, the use of empirical equations, and the choice of parameterization schemes. However, it is still possible to use the same equation formula, such as the soil temperature diffusion equation for calculating soil temperature [98], the Richard equation for calculating water movement of unsaturated soil [99], and the Farquhar and Collatz photosynthesis models for simulating vegetation photosynthesis $[100,101]$. Eco-hydrological models may involve many variables [102], e.g., meteorological variables (rainfall, radiation, and evaporation, etc.), hydrological variables (water level, water discharge, and flow velocity, etc.), and ecological variables (vegetation and its net primary productivity, plankton, and benthos, etc.). Existing studies mainly focus on experimental observation, mechanism exploration, and numerical simulation toward ecosystems to discuss carbon flux, soil water transfer, evaporation, and soil water-related parameter observation at a point or field scale [102], but the interaction mechanism of eco-hydrological processes at the watershed and even the global scale is worthy of more exploration. For future research on coupling models, we suggest the following:

1. Models should contain sufficient ecological and hydrological processes and their interactions. The continuity and heterogeneity of ecological and hydrological processes should be comprehensively revealed through site monitoring, laboratory experiments, or numerical simulation methods [102], as well as the multi-scale and multi-variable simulations, to comprehensively identify eco-hydrological processes in a changing environment. To clarify the migration and transformation of rules and the evolution characteristics of variables in the SPAC interface, and to explore the spatiotemporal distribution of key eco-hydrological variables, it is helpful to comprehensively analyze eco-hydrological evolution characteristics and driving mechanisms. However, this means more parameters and variations, increasing the complexity of the model, and therefore, the trade-off should be considered.

2. The selected processes need to be simulated as accurately as possible. Appropriate equations should be selected based on the conditions of planning areas to improve the accuracy of the selected parameters, and the redundancy or overlap of parameters should be observed. Models should be combined with local, social, economic, and environmental conditions because future research on coupling models is not so much to obtain a number of ESs, generally provided by the GSI, that can be used directly in all planning areas, but a way to encourage planners to adjust the models and re-simulate them to identify a balanced response between ecological and hydrological processes for each planning. Meanwhile, improving the resolution of the model simulation as much as possible is significant, then the number of ESs provided by GSI can be identified locally. Furthermore, the coupling study of hydro-ecological models is affected by inherent data uncertainty, and ignoring the uncertainty will lead to errors in model parameters, unreliable predictions, and vicious management decision making [103]. The sources of uncertainty can be roughly divided into uncertainties 
related to model input, model structure, parameters, and observations used for model calibration [104]. It is estimated that the sources of uncertainty in complex models are still in the initial stage, and more experimental research and summary can be conducted to reduce the uncertainty.

3. The basic framework, theoretical system, and technical methods of eco-hydrology should be improved. The mismatch of spatial and temporal scales between ecohydrological processes is always a challenge for coupling research. Theoretically, the small-scale simulation is closer to the actual situation, but the current smallscale research conclusions are difficult to be extended to watersheds or other largescale systems [105]. Hydrological models usually use a daily scale, while ecological models usually use an hourly scale, and downscaling or upscaling approaches can be used to achieve the dynamic calculation of exchange variables and scale conversion among modules.

4. The response of eco-hydrological mechanisms to global changes, such as climate change and human impact, should be considered. Interfaces with socio-economic models and climate change models should be constructed in eco-hydrological coupling models, so as to identify the necessary response mechanisms of eco-hydrological processes under the common influence of climate change and urbanization.

\subsubsection{Site Selection}

Site selection by means of remote sensing is a widely used method; the most common approach is to generalize the planning area via the Geographic Information System (GIS) and to construct a GSI evaluation system suitable for construction with the MCDA framework to obtain the evaluation results, then to select the sites based on economic, social, and ecological conditions in areas with higher suitability. Similar to the studies in type/scenario evaluation, site selection also involves multi-standard evaluation. MCDA can logically structure complex issues and specify various uncertainties; therefore, all specifications for the site selection of GSI involve MCDA [73]. AHP is also widely used in the index weight determination process [33,106]. The layer-cake theory proposed by McHarg [107] guides the site selection plan. Although planners select different numbers and types of social, economic, and environmental indicators, the overlay analysis of construction suitability indicators is evaluated on land grids of different resolutions essentially. It is worth mentioning that related studies use different terms, such as suitability, sensitivity, or vulnerability. We do not make a distinction because these terms are similar; planners are all committed to choosing the most vulnerable areas with the highest demand for GSI construction. GIS provides convenience to visualize the evaluation results of the suitability of GSI construction. It is worth noting that most of the existing suitability studies still focus on the environment dimension, and therefore, the evaluation framework for suitability may only deal with environmental indicators (e.g., slope, elevation, water body, and ecological land). However, GSI should never be separated from human society with the exclusive consideration of the environment. Although the objective of GSI planning is water quantity and water quality regulation services, the complex interaction of hydrological and ecological processes existing in GSI in the social-ecological system makes the comprehensive consideration of hydrological, ecological, and social benefits indispensable. The key to site selection is to harvest more potential benefits on the basis of achieving planning objectives. Researchers have begun to incorporate GSI into the social-ecological system, considering the interaction of multiple processes of ecology, hydrology, and social economy involved in GSI, with more attention paid to public participation. Therefore, both the construction suitability indicators (slope, elevation, land use type, etc.) and the requirement indicators of hydrological, ecological, and social benefits (runoff coefficient, ecological sensitivity, social sensitivity, etc.) all need to be considered in the evaluation framework. In addition, for the site selection of different types and scales of GSI, the evaluation should be further adjusted in each planning to ensure that the sites of GSI are located in the most suitable and most needed areas. 


\subsection{The Ecosystem Aspect}

\subsubsection{Ecosystem Resilience}

Disturbances such as urbanization and climate change affect the GSI facility as well as the entire ecosystem where GSI operates. As previously discussed, GSI is influenced by the interaction of ecological and hydrological processes in the ecosystem of the GSI planning framework; therefore, it is necessary to consider the ecosystem aspect, to which the concept of ecosystem resilience greatly contributes. The concept of resilience was introduced into the field of ecology in 1973 by Holling [108], who defined it as "a measure of the persistence of systems and of their ability to absorb change and disturbance and still maintain the same relationships between populations or state variables". Since then, many scholars have been devoted to clarifying the definition of resilience [109-111]. A clear formulation and application of ecological resilience can provide a basis for improving the ability of an ecosystem to cope with stressors and disturbances and help them tide over the reorganization period [37]. Systems with high resilience can absorb changes and maintain the same state in a series of disturbances and management actions [112]; these systems may possess favorable environmental conditions, strong multi-scale feedback, and a high level of diversity and redundancy [37]. As a comparison, systems with low resilience may react strongly to disturbances and move to another state [112], and these systems may contain poor environmental conditions, insufficiency of species or functional groups, and disturbances exceeding the range of historical changes [37]. Managers coping with the latter type of systems face the greatest challenge because they usually need to manage the systems actively. After management behavior improves the conditions, systems with high adaptability may be reorganized and restored to their original state [37]. Therefore, regarding the ecosystem aspect, if resilience is high enough, the ecosystem can absorb disturbances and return to the state before the disturbances, and the processes in the system can still operate normally; that is, ecological and hydrological processes can interact continuously and steadily. As a result, the management and promotion of ecosystem resilience is the guarantee for the stable operation of GSI. Therefore, the different purposes of facility and ecosystem aspects are obvious- the former is to harvest various ES from facilities directly, while the latter is to ensure that hydrological and ecological processes can maintain stable interaction in response to disturbances to indirectly support the continuous provision of ES.

Thus far, most studies have focused on theories, definitions, and conceptualizations to understand ecological resilience, focusing on the response of species diversity and functions to stress and disturbance on a small (i.e., local) scale [37]. In fact, integrating the concept of ecosystem resilience with landscape patterns provides an approach to understanding how ecosystem attributes and processes interact with landscape structure to affect ecosystem responses to disturbances and how the ecosystem supports resources, habitats, and species [37]. In the context of landscape, this integration provides a way of understanding the aforementioned processes within the ecosystem. Resilience-based management uses a spatially clear approach and contributes to selecting the type of management action that is most likely to succeed [37]. Ahern [113] explained the relationship of landscape composition, structure, and dynamics with resilience, and pointed out that a reasonable landscape pattern plays a significant role in buffering risks and helps the system to recover from disturbances. Therefore, landscape pattern optimization based on the interaction of spatial pattern and ecological processes can be an approach to the management and promotion of ecosystem resilience, as it provides a "spatial language" for concretely describing the interrelationship and the dynamics of spatiotemporal scales between landscape structure and function. Landscape patterns can be summarized as the shape, proportion, and spatial distribution of landscape elements. Patches, corridors, and matrices are the basic elements of landscape patterns, which are related to ecological processes in the landscape and affect the distribution and layout of resources and the physical environment. Landscape pattern optimization is essential to adjust the spatial structure of the landscape, with the goal of enhancing the integrity and connectivity of the 
ecosystem and building a spatial pattern that maintains the regional ecological processes. The "patches-corridor-matrix" theory in landscape ecology is often used in landscape pattern optimization to identify and reorganize the key components of landscape patterns (i.e., patches, corridors, nodes, and matrices), which guide the protection and restoration of these components that are vital to the provision of expected ESs. The optimization process helps improve the integrity, connectivity, and diversity of landscape patterns, build ecological networks, enhance regional ecosystem resilience, protect or restore biodiversity, and sustainably provide multiple ESs [114]. Fu et al. [114] used InVEST software to evaluate two typical ecosystem services (water production and habitat quality) to identify ecological sources, and selected the minimum cumulative resistance model to identify ecological corridors; the landscape pattern was optimized by the improvement and reorganization of ecological sources to strengthen the material and energy flow between ecological sources and provide channels for species migration.

\subsubsection{Quantitative Assessment of Ecosystem Resilience}

Obviously, a quantitative assessment of resilience is a way to visually express the results of resilience promotion management, but there is no single measurable variable that can represent ecosystem resilience. Relevant studies mostly evaluate urban resilience from the aspects of infrastructure, society, economy, and ecology [115]. Liu et al. [116] built an index system including diversity, connectivity, decentralization, and ecosystem service provision to assess the resilience of Shenyang, China, and established a link between resilience and landscape characteristics to guide the planning practice. Yi et al. [38] divided the existing quantitative assessment studies of resilience into three categories -forest resilience, soil microbial community resilience, and hydrological resilience; they found that many variables (e.g., tree-ring width, NDVI, microbiome mass, and catchment evapotranspiration index) can be used as indicators of system state variables, but it is hard to tell which one is better, as it depends on the objective and data availability in each study. They also pointed out that the measurement of resilience is not actually measuring itself, but its components, such as resistance, recovery, or combinations of them, i.e., elasticity. Dynamic system theory is a fundamental base of resilience research [38]. The uncertainty of resilience is based on the complexity of the nonlinear system, which contains many positive and negative feedback loops. Resistance, recovery, and resilience are the results of competition and cooperation between these feedback loops. Therefore, policymakers should understand the feedback structure of the nonlinear social-ecological system, and manage the related feedback loops to reduce disturbances or accelerate recovery, or to prevent the system from entering a new stable steady state [38]. In the future, it is necessary to grasp how to manage the dominant feedback to avoid catastrophic disasters.

As a matter of fact, the management of ecosystem resilience can bring many benefits, not just in terms of the ESs discussed in this review, but also the benefits of resources, habitats, and populations, etc. [37]. We focus on the effect of resilience promotion on the interaction between ecological and hydrological processes within the ecosystem. Future GSI planning should integrate facility and ecosystem aspects to explore the specific quantitative benefits of ecosystem resilience to the GSI system, and take more types of ESs into consideration. We recommend managing ecosystem resilience to ensure the stable operation of the GSI system through landscape pattern optimization. Exploring the interaction between the two aspects is also a point that needs to be considered in the future, for example, whether an ecosystem with high resilience can reduce GSI investment. We hold the assertion that the consideration of the two aspects in the GSI planning framework is equally crucial, and planners should strive to take into account both facility and ecosystem aspects when developing an overall understanding of the conditions in the study areas, so as to obtain ES in a comprehensive and sustainable manner. The quantitative assessment of ecosystem resilience also deserves more in-depth discussions in the future. A feasible solution is to select the indicators that can characterize the landscape pattern in view of the affirmation of landscape pattern optimization as an approach to enhancing ecological resilience, then 
to determine the weights of selected indicators through appropriate methods, finally to form an evaluation system following the interaction mechanism of the eco-hydrological processes. In addition, the effective cooperation among managers, planners, scholars, and stakeholders helps to develop resilience-based management measures to strengthen and restore the ecosystem.

\subsection{Limitations}

This review included only 158 articles, although they help to identify the current research status of GSI planning regarding both facility and ecosystem aspects, and are the basis for us to predict future research directions, the papers that were not contained may contradict this review, which means the scope of follow-up studies needs to be expanded. We focused on water quality and water quantity regulation, but GSI practice has been extended to many areas of society, economy, and ecology. Therefore, it is inevitable for future research to explore more types of ESs in the social-ecological system, which is attached to greater complexity. In addition, the GSI planning framework we proposed may not be detailed enough, as some default planning steps were omitted. The objective formulation also includes steps such as collecting information on the conditions of the study areas; further, we did not describe the types of information required in detail, which may need to be discussed in forthcoming research.

In addition, most of the evaluation studies analyzing the performances of GSI were carried out in the laboratory or monitored conditions after the implementation of GSI planning. We do not deny the contribution of these evaluation articles to GSI and even agree with its positive effects. Although feedbacks can be given to GSI planning by evaluating its performances, the evaluation should be accomplished by the researcher through a long period of monitoring, and there are still many deficiencies in the pre-planning steps (i.e., objective formulation, type/scenario evaluation, quantity/scale determination, and site selection); therefore, the related articles regarding the performance evaluation of GSI were not considered as a planning step of the GSI planning framework in this review. It is worth mentioning that although we did not discuss the evaluation of GSI's performances in detail, we reviewed and quoted some relevant papers in the steps of objective formulation and type/scenario evaluation to support our arguments.

\section{Conclusions}

We developed a GSI planning framework that integrates the aspects of facility and ecosystems and made suggestions for future GSI planning to harvest stormwater management ESs through reviewing and synthesizing the literature. Regarding the facility aspect, quantitative and clear objectives are decisive for the entire GSI planning, since the social, economic, and environmental characteristics between study areas are discrepant; therefore, it is recommended that relevant authorities provide references to planning objectives that can vary with regional characteristics. It is foreseeable that these references should be scopes rather than a fixed value, thus allowing the actual planning to formulate clear objectives based on the trade-off of multiple anticipated ESs. Integrating indicators of multiple dimensions of social, economic, and environmental sustainability to evaluate GSI types/scenarios via MCDA and reinforce the sustainability of the GSI planning is the future research focus of type/scenario evaluation. Developing coupling models of hydrology and ecology to explore the quantitative relationship between the GSI type/scenario and the planning objective is the focus of future research; moreover, difficulty in difficulty in the determination of quantity/scale and finding the appropriate quantity/scale will receive much attention from stakeholders, which is helpful to the development of GSI. However, improving the completeness and accuracy of the coupling models will definitely increase the complexity in the meantime, and therefore, this trade-off needs to be considered in depth. A key factor in site selection is to evaluate the construction suitability of pixels in the study area based on the layer-cake theory, through which multiple considerations of social, economic, and environmental criteria should be covered. 
In addition, the success of GSI planning is determined by the GSI facilities themselves as well as, the ecosystem, which also has a critical influence. Therefore, regarding the ecosystem aspect, in order to ensure that the ecosystem can withstand disturbances and still maintain the stable interaction of ecological and hydrological processes, and indirectly guarantee continuous ES production, we discussed the benefits of promoting ecosystem resilience. We suggested adopting landscape pattern optimization as an approach to resilience promotion, while it is necessary to consider more comprehensive and specific ways in the future. In addition, Future GSI planning should integrate facility and ecosystem aspects to explore the specific quantitative benefits of ecosystem resilience to the GSI system, and take more types of ESs into consideration. The quantitative assessment of ecosystem resilience also deserves more in-depth discussions. A feasible solution is to select the indicators that can characterize landscape patterns resulting from landscape pattern optimization as an approach to enhancing ecological resilience, then to determine the weights of selected indicators through appropriate methods, and finally, to form an evaluation system following the interaction mechanism of eco-hydrological processes. Exploring the interaction between these two aspects is also a point that needs to be considered in the future, for example. whether an ecosystem with high resilience can reduce GSI investment. We hold the assertion that the consideration of the two aspects in the GSI planning framework is equally crucial, and planners should strive to take into account both facility and ecosystem aspects when developing an overall understanding of the conditions in the studied areas. In addition, effective cooperation among managers, planners, scholars, and stakeholders helps to develop resilience-based management measures to strengthen and restore the ecosystem.

The most critical part that needs to be explored in detail urgently in this framework is the determination of quantity/scale. To advance the research in this area, we developed an indirect quantitative approach, where the relationship between GSI and ES is quantified precisely and operationally through a deep understanding, resulting from accurate simulations, of the interaction mechanism of ecological and hydrological processes. We encourage generating hydrological and ecological coupling simulations based on local social, economic, and environmental conditions in each planning scenario, then understanding the interaction mechanism between hydrological and ecological processes and identifying the interactions and changes in eco-hydrological processes caused by the ecological processes introduced by GSI. As a result, the number of ESs can be analyzed in accordance with these interactions and changes, as well as the quantitative relationship between GSI and ES that will instruct other steps of GSI planning. This approach is consistent with the spatiotemporal heterogeneity of the performance of GSI facilities. Furthermore, GSI planning using explicit data will be advantageous for its promotion, construction, and the reduction in the planners' and investors' concerns about selecting GSI as an alternative.

Supplementary Materials: The following are available online at https:/ / www.mdpi.com/article/ $10.3390 /$ su132413942/s1.

Author Contributions: Conceptualization, G.L.; methodology, G.L.; resources, G.L.; writingoriginal draft preparation, G.L.; writing-review and editing, G.L. and L.W.; supervision, L.W.; project administration, L.W.; funding acquisition, L.W. All authors have read and agreed to the published version of the manuscript.

Funding: This research was funded by the National Key Research and Development Program of China (NO. 2018YFC0408000, 2018YFC0408004) and the Jinan Water Science and Technology Project (NO. JNSWKJ202103).

Institutional Review Board Statement: Not Applicable.

Informed Consent Statement: Not Applicable.

Data Availability Statement: Not Applicable. 
Conflicts of Interest: The authors declare no conflict of interest. The funders had no role in the design of the study; in the collection, analyses, or interpretation of data; in the writing of the manuscript, or in the decision to publish the results.

\section{References}

1. Dhakal, K.P.; Chevalier, L.R. Implementing Low Impact Development in Urban Landscapes: A Policy Perspective. In World Environmental and Water Resources Congress 2015: Floods, Droughts, and Ecosystems, Austin, USA; Karvazy, K., Chevalier, L.R., Eds.; American Society of Civil Engineers: New York, NY, USA, 2015.

2. Kim, J.-H.; Kim, H.Y.; Demarie, F. Facilitators and Barrier s of Applying Low Impact Development Practices in Urban Development. Water Resour. Manag. 2017, 31, 3795-3808. [CrossRef]

3. Ahiablame, L.M.; Engel, B.A.; Chaubey, I. Effectiveness of Low Impact Development Practices: Literature Review and Suggestions for Future Research. Water Air Soil Pollut. 2012, 223, 4253-4273. [CrossRef]

4. Bichai, F.; Ashbolt, N. Public health and water quality management in low-exposure stormwater schemes: A critical review of regulatory frameworks and path forward. Sustain. Cities Soc. 2017, 28, 453-465. [CrossRef]

5. Varotsos, C.A.; Efstathiou, M.N.; Cracknell, A.P. On the scaling effect in global surface air temperature anomalies. Atmospheric Chem. Phys. Discuss. 2013, 13, 5243-5253. [CrossRef]

6. Karamouz, M.; Hosseinpour, A.; Nazif, S. Improvement of Urban Drainage System Performance under Climate Change Impact: Case Study. J. Hydrol. Eng. 2010, 16, 395-412. [CrossRef]

7. Dong, X.; Guo, H.; Zeng, S. Enhancing future resilience in urban drainage system: Green versus grey infrastructure. Water Res. 2017, 124, 280-289. [CrossRef]

8. Sohn, W.; Kim, J.-H.; Li, M.-H.; Brown, R. The influence of climate on the effectiveness of low impact development: A systematic review. J. Environ. Manag. 2019, 236, 365-379. [CrossRef]

9. Akhter, F.; Hewa, G.A.; Ahammed, F.; Myers, B.; Argue, J.R. Performance Evaluation of Stormwater Management Systems and Its Impact on Development Costing. Water 2020, 12, 375. [CrossRef]

10. Akther, M.; He, J.; Chu, A.; Huang, J.; Van Duin, B. A Review of Green Roof Applications for Managing Urban Stormwater in Different Climatic Zones. Sustainability 2018, 10, 2864. [CrossRef]

11. Conley, G.; Beck, N.; Riihimaki, C.A.; Tanner, M. Quantifying clogging patterns of infiltration systems to improve urban stormwater pollution reduction estimates. Water Res. X 2020, 7, 100049. [CrossRef]

12. Sanicola, O. Using Permeable Pavements to Reduce the Environmental Impacts of Urbanisation. Int. J. Geomate 2018, 14, 159-166. [CrossRef]

13. Qin, H.-P.; Li, Z.-X.; Fu, G.T. The effects of low impact development on urban flooding under different rainfall characteristics. J. Environ. Manag. 2013, 129, 577-585. [CrossRef]

14. Wright, S.P.; Santelmann, M.V.; Vache, K.B.; Hulse, D.W. Modeling the impact of development policies and climate on sub-urban watershed hydrology near Portland, Oregon. Landsc. Urban Plan. 2021, 214, 104133. [CrossRef]

15. Eckart, K.; McPhee, Z.; Bolisetti, T. Performance and implementation of low impact development-A review. Sci. Total Environ. 2017, 607, 413-432. [CrossRef] [PubMed]

16. Son, C.H.; Hyun, K.H.; Kim, D.; Baek, J.I.; Ban, Y.U. Development and Application of a Low Impact Development (LID)-Based District Unit Planning Model. Sustainability 2017, 9, 145. [CrossRef]

17. EPA. What Is Green Infrastructure? Available online: http://www2.epa.gov/greeninfrastructure/what-green-infrastructure (accessed on 17 June 2021).

18. Matsler, M.; Meerow, S.; Mell, I.C.; Pavao-Zuckerman, M.A. A 'green' chameleon: Exploring the many disciplinary definitions, goals, and forms of "green infrastructure". Landscape Urban Plan. 2021, 214, 104145. [CrossRef]

19. Flynn, C.D.; Davidson, C.I. Adapting the social-ecological system framework for urban stormwater management: The case of green infrastructure adoption. Ecol. Soc. 2016, 21, 19. [CrossRef]

20. Prudencio, L.; Null, S. Stormwater management and ecosystem services: A review. Environ. Res. Lett. 2018, 13, 033002. [CrossRef]

21. Guerrero, J.; Alam, T.; Mahmoud, A.; Jones, K.D.; Ernest, A. Decision-Support System for LID Footprint Planning and Urban Runoff Mitigation in the Lower Rio Grande Valley of South Texas. Sustainability 2020, 12, 3152. [CrossRef]

22. Bautista, D.; Peña-Guzmán, C. Simulating the Hydrological Impact of Green Roof Use and an Increase in Green Areas in an Urban Catchment with i-Tree: A Case Study with the Town of Fontibón in Bogotá, Colombia. Resources 2019, 8, 68. [CrossRef]

23. Kim, J.; Ryu, J.H. Decision-Making of LID-BMPs for Adaptive Water Management at the Boise River Watershed in a Changing Global Environment. Water 2020, 12, 2436. [CrossRef]

24. Tuttolomondo, T.; Virga, G.; Licata, M.; Leto, C.; La Bella, S. Constructed Wetlands as Sustainable Technology for the Treatment and Reuse of the First-Flush Stormwater in Agriculture-A Case Study in Sicily (Italy). Water 2020, 12, 2542. [CrossRef]

25. Venter, Z.S.; Barton, D.N.; Martinez-Izquierdo, L.; Langemeyer, J.; Baró, F.; McPhearson, T. Interactive spatial planning of urban green infrastructure-Retrofitting green roofs where ecosystem services are most needed in Oslo. Ecosyst. Serv. 2021, 50, 101314. [CrossRef]

26. Jessup, K.; Parker, S.S.; Randall, J.M.; Cohen, B.S.; Roderick-Jones, R.; Ganguly, S.; Sourial, J. Planting Stormwater Solutions: A methodology for siting nature-based solutions for pollution capture, habitat enhancement, and multiple health benefits. Urban For. Urban Green. 2021, 64, 127300. [CrossRef] 
27. Hale, R.; Swearer, S.E.; Sievers, M.; Coleman, R. Balancing biodiversity outcomes and pollution management in urban stormwater treatment wetlands. J. Environ. Manag. 2019, 233, 302-307. [CrossRef] [PubMed]

28. Darnthamrongkul, W.; Mozingo, L.A. Toward sustainable stormwater management: Understanding public appreciation and recognition of urban Low Impact Development (LID) in the San Francisco Bay Area. J. Environ. Manag. 2021, $300,113716$. [CrossRef] [PubMed]

29. Cortinovis, C.; Geneletti, D. Ecosystem services in urban plans: What is there, and what is still needed for better decisions. Land Use Policy 2018, 70, 298-312. [CrossRef]

30. Albert, C.; Galler, C.; Hermes, J.; Neuendorf, F.; von Haaren, C.; Lovett, A. Applying ecosystem services indicators in landscape planning and management: The ES-in-Planning framework. Ecol. Indic. 2016, 61, 100-113. [CrossRef]

31. Salata, S.; Giaimo, C.; Barbieri, C.A.; Garnero, G. The utilization of ecosystem services mapping in land use planning: The experience of LIFE SAM4CP project. J. Environ. Plan. Manag. 2020, 63, 523-545. [CrossRef]

32. Koc, K.; Ekmekcioğlu, Ö.; Özger, M. An integrated framework for the comprehensive evaluation of low impact development strategies. J. Environ. Manag. 2021, 294, 113023. [CrossRef]

33. Zhang, X.Y.; Chen, L.; Zhang, M.; Shen, Z.Y. Prioritizing sponge city sites in rapidly urbanizing watersheds using multi-criteria decision model. Environ. Sci. Pollut. Res. 2021, 28, 63377-63390. [CrossRef]

34. Li, N.; Qin, C.; Du, P. Optimization of China Sponge City Design: The Case of Lincang Technology Innovation Park. Water 2018, 10, 1189. [CrossRef]

35. Shao, H.; Song, P.; Mu, B.; Tian, G.; Chen, Q.; He, R.; Kim, G. Assessing city-scale green roof development potential using Unmanned Aerial Vehicle (UAV) imagery. Urban For. Urban Green. 2021, 57, 126954. [CrossRef]

36. Sochacka, B.A.; Bos, J.J.; Dobbie, M.F. Contextualising landscape perceptions: The role of urban landscape, ecosystem and water system in formation of mental models of a stormwater wetland in Brisbane. Landsc. Ecol. 2021, 36, 2599-2617. [CrossRef]

37. Chambers, J.C.; Allen, C.R.; Cushman, S.A. Operationalizing Ecological Resilience Concepts for Managing Species and Ecosystems at Risk. Front. Ecol. Evol. 2019, 7, 241. [CrossRef]

38. Yi, C.X.; Jackson, N. A review of measuring ecosystem resilience to disturbance. Environ. Res. Lett. 2021, 16, 053008. [CrossRef]

39. Jaiswal, D.; Pandey, U.; Mishra, V.; Pandey, J. Integrating resilience with functional ecosystem measures: A novel paradigm for management decisions under multiple-stressor interplay in freshwater ecosystems. Glob. Chang. Biol. 2021, 27, 3699-3717. [CrossRef] [PubMed]

40. Alikhani, J.; Nietch, C.; Jacobs, S.; Shuster, B.; Massoudieh, A. Modeling and Design Scenario Analysis of Long-Term Monitored Bioretention System for Rainfall-Runoff Reduction to Combined Sewer in Cincinnati, OH. J. Sustain. Water Built Environ. 2020, 6 , 04019016. [CrossRef]

41. Zhang, L.; Oyake, Y.; Morimoto, Y.; Niwa, H.; Shibata, S. Rainwater storage/infiltration function of rain gardens for management of urban storm runoff in Japan. Landsc. Ecol. Eng. 2019, 15, 421-435. [CrossRef]

42. Zhang, Q.Q.; Miao, L.P.; Wang, X.K.; Liu, D.D.; Zhu, L.; Zhou, B.; Sun, J.C.; Liu, J.T. The capacity of greening roof to reduce stormwater runoff and pollution. Landsc. Urban Plan. 2015, 144, 142-150. [CrossRef]

43. Zheng, X.Z.; Zou, Y.C.; Lounsbury, A.W.; Wang, C.; Wang, R.R. Green roofs for stormwater runoff retention: A global quantitative synthesis of the performance. Resour. Conserv. Recycl. 2021, 170, 105577. [CrossRef]

44. Flores, P.D.; Maniquiz, M.C.; Tobio, J.A.S.; Kim, L.-H. Evaluation on the Hydrologic Effects after Applying an Infiltration Trench and a Tree Box Filter as Low Impact Development (LID) Techniques. J. Korean Soc. Water Environ. 2015, 31, 12-18. [CrossRef]

45. Locatelli, L.; Mark, O.; Mikkelsen, P.S.; Arnbjerg-Nielsen, K.; Wong, T.; Binning, P.J. Determining the extent of groundwater interference on the performance of infiltration trenches. J. Hydrol. 2015, 529, 1360-1372. [CrossRef]

46. Tirpak, R.A.; Winston, R.J.; Feliciano, M.; Dorsey, J.D.; Epps, T.H. Impacts of permeable interlocking concrete pavement on the runoff hydrograph: Volume reduction, peak flow mitigation, and extension of lag times. Hydrol. Process. 2021, 35, e14167. [CrossRef]

47. Fu, X.R.; Liu, J.H.; Shao, W.W.; Mei, C.; Wang, D.; Yan, W.C. Evaluation of Permeable Brick Pavement on the Reduction of Stormwater Runoff Using a Coupled Hydrological Model. Water 2020, 12, 2821. [CrossRef]

48. Mahmoud, A.; Alam, T.; Sanchez, A.; Guerrero, J.; Oraby, T.; Ibrahim, E.; Jones, K.D. Stormwater Runoff Quality and Quantity from Permeable and Traditional Pavements in Semiarid South Texas. J. Environ. Eng. 2020, 146, 05020001. [CrossRef]

49. Jennings, A.A.; Adeel, A.A.; Hopkins, A.; Litofsky, A.L.; Wellstead, S.W. Rain Barrel-Urban Garden Stormwater Management Performance. J. Environ. Eng. 2013, 139, 757-765. [CrossRef]

50. Oberascher, M.; Zischg, J.; Palermo, S.A.; Kinzel, C.; Rauch, W.; Sitzenfrei, R. Smart Rain Barrels: Advanced LID Management Through Measurement and Control. In Proceedings of the 11th International Conference on Urban Drainage Modelling (UDM), Palermo, Italy, 23-26 September 2018; Mannina, G., Ed.; Springer International Publishing Aggewerbestrasse 11: Cham, Switzerland, 2019. [CrossRef]

51. Ahiablame, L.M.; Engel, B.A.; Chaubey, I. Effectiveness of low impact development practices in two urbanized watersheds: Retrofitting with rain barrel/cistern and porous pavement. J. Environ. Manag. 2013, 119, 151-161. [CrossRef]

52. Winston, R.J.; Powell, J.T.; Hunt, W.F. Retrofitting a grass swale with rock check dams: Hydrologic impacts. Urban Water J. 2019, 16, 404-411. [CrossRef]

53. Zhang, W.; Zhang, X.Y.; Shi, Z.N.; Zhang, D.W.; Li, S.M. Performance and potential on TSS removal of grassed swales in simulated rainfall events. Desalin. Water Treat. 2018, 119, 160-165. [CrossRef] 
54. Shafique, M.; Kim, R.; Kyung-Ho, K. Evaluating the Capability of Grass Swale for the Rainfall Runoff Reduction from an Urban Parking Lot, Seoul, Korea. Int. J. Environ. Res. Public Health 2018, 15, 537. [CrossRef]

55. Liu, T.Q.; Lawluvy, Y.; Shi, Y.; Yap, P.S. Low Impact Development (LID) Practices: A Review on Recent Developments, Challenges and Prospects. Water Air Soil Pollut. 2021, 232, 1-36. [CrossRef]

56. Huang, J.; Yu, Z.B.; Qin, Y.H.; Wang, L.; Huang, Y.Y.; Huang, Y.M. A case in subtropical climate city: Assessing the bioretention hydraulic performance on storm in response to poor permeability soil. J. Environ. Manag. 2021, 293, 112952. [CrossRef]

57. Wang, M.; Zhang, D.Q.; Wang, Z.L.; Zhou, S.Q.; Tan, S.K. Long-term performance of bioretention systems in storm runoff management under climate change and life-cycle condition. Sustain. Cities Soc. 2021, 65, 102598. [CrossRef]

58. Xiong, J.Q.; Ren, S.H.; He, Y.F.; Wang, X.C.; Bai, X.X.; Wang, J.X.; Dzakpasu, M. Bioretention cell incorporating Fe-biochar and saturated zones for enhanced stormwater runoff treatment. Chemosphere 2019, 237, 124424. [CrossRef]

59. Li, Y.Q.; Zhang, Y.; Yu, H.; Han, Y.; Zuo, J.N. Enhancing nitrate removal from urban stormwater in an inverted bioretention system. Ecol. Eng. 2021, 170, 106315. [CrossRef]

60. Xiong, J.Q.; Zhu, J.G.; Li, G.H.; Yang, Y.; An, S.X.; Liu, C.K.; Wang, J.X. Purification effect of bioretention with improved filler on runoff pollution under low temperature conditions. J. Environ. Manag. 2021, 295, 113065. [CrossRef]

61. Kohlsmith, E.; Morse, J.; Poor, C.; Law, J. Stormwater Treatment Effectiveness of Established Lined Bioretention Facilities in Portland, Oregon. J. Sustain. Water Built Environ. 2021, 7, 05021002. [CrossRef]

62. Woodruff, S.C.; BenDor, T.K. Ecosystem services in urban planning: Comparative paradigms and guidelines for high quality plans. Landsc. Urban Plan. 2016, 152, 90-100. [CrossRef]

63. Albert, C.; Aronson, J.; Fürst, C.; Opdam, P. Integrating ecosystem services in landscape planning: Requirements, approaches, and impacts. Landsc. Ecol. 2014, 29, 1277-1285. [CrossRef]

64. Mascarenhas, A.; Ramos, T.; Haase, D.; Santos, R. Integration of ecosystem services in spatial planning: A survey on regional planners' views. Landsc. Ecol. 2014, 29, 1287-1300. [CrossRef]

65. Peña, L.; De Manuel, B.F.; Méndez-Fernández, L.; Viota, M.; Ametzaga-Arregi, I.; Onaindia, M. Co-Creation of Knowledge for Ecosystem Services Approach to Spatial Planning in the Basque Country. Sustainability 2020, 12, 5287. [CrossRef]

66. Cortinovis, C.; Geneletti, D.; Hedlund, K. Synthesizing multiple ecosystem service assessments for urban planning: A review of approaches, and recommendations. Landsc. Urban Plan. 2021, 213, 104129. [CrossRef]

67. Cortinovis, C.; Geneletti, D. A framework to explore the effects of urban planning decisions on regulating ecosystem services in cities. Ecosyst. Serv. 2019, 38, 100946. [CrossRef]

68. Bennett, E.M.; Chaplin-Kramer, R. Science for the sustainable use of ecosystem services. F1000Research 2016, 5, 2622. [CrossRef] [PubMed]

69. Geneletti, D. Reasons and options for integrating ecosystem services in strategic environmental assessment of spatial planning. Int. J. Biodivers. Sci. Ecosyst. Serv. Manag. 2011, 7, 143-149. [CrossRef]

70. Xu, H.; Chen, L.; Zhao, B.; Zhang, Q.; Cai, Y. Green stormwater infrastructure eco-planning and development on the regional scale: A case study of Shanghai Lingang New City, East China. Front. Earth Sci. 2015, 10, 366-377. [CrossRef]

71. Technical Guidance on Implementing the Stormwater Runoff Requirements for Federal Projects under Section 438 of the Energy Independence and Security Act. Available online: https://www.epa.gov/sites/default/files/2015-09/documents/eisa-438.pdf (accessed on 1 July 2021).

72. Technical Guide for Sponge City Construction. Available online: http://appendix.changchun.gov.cn/32fgw/uploads/soft/1612 20/17_1409416801.pdf (accessed on 20 September 2021).

73. Roggero, M. Social dilemmas, policy instruments, and climate adaptation measures: The case of green roofs. Mitig. Adapt. Strat. Glob. Chang. 2020, 25, 625-642. [CrossRef]

74. Hua, P.; Yang, W.Y.; Qi, X.C.; Jiang, S.S.; Xie, J.Q.; Gu, X.Y.; Li, H.H.; Zhang, J.; Krebs, P. Evaluating the effect of urban flooding reduction strategies in response to design rainfall and low impact development. J. Clean. Prod. 2020, 242, 118515. [CrossRef]

75. Kourtis, I.M.; Tsihrintzis, V.A.; Baltas, E. A robust approach for comparing conventional and sustainable flood mitigation measures in urban basins. J. Environ. Manag. 2020, 269, 110822. [CrossRef]

76. Liang, C.M.; Zhang, X.; Xu, J.; Pan, G.Y.; Wang, Y. An integrated framework to select resilient and sustainable sponge city design schemes for robust decision making. Ecol. Indic. 2020, 119, 106810. [CrossRef]

77. Darko, A.; Chan, A.P.C.; Ameyaw, E.E.; Owusu, E.K.; Parn, E.; Edwards, D.J. Review of application of analytic hierarchy process (AHP) in construction. Int. J. Constr. Manag. 2019, 19, 436-452. [CrossRef]

78. Men, H.; Lu, H.; Jiang, W.J.; Xu, D. Mathematical Optimization Method of Low-Impact Development Layout in the Sponge City. Math. Probl. Eng. 2020, 2020, 6734081. [CrossRef]

79. Raei, E.; Alizadeh, M.R.; Nikoo, M.R.; Adamowski, J. Multi-objective decision-making for green infrastructure planning (LIDBMPs) in urban storm water management under uncertainty. J. Hydrol. 2019, 579, 124091. [CrossRef]

80. Scott, R.L.; Cable, W.L.; Hultine, K.R. The ecohydrologic significance of hydraulic redistribution in a semiarid savanna. Water Resour. Res. 2008, 44, W02440. [CrossRef]

81. Nocco, M.A.; Rouse, S.E.; Balster, N.J. Vegetation type alters water and nitrogen budgets in a controlled, replicated experiment on residential-sized rain gardens planted with prairie, shrub, and turfgrass. Urban Ecosyst. 2016, 19, 1665-1691. [CrossRef]

82. Jarden, K.M.; Jefferson, A.J.; Grieser, J.M. Assessing the effects of catchment-scale urban green infrastructure retrofits on hydrograph characteristics. Hydrol. Process. 2016, 30, 1536-1550. [CrossRef] 
83. Bach, P.M.; Kuller, M.; Deletic, A. A spatial planning-support system for generating decentralised urban stormwater management schemes. Sci. Total Environ. 2020, 726, 138282. [CrossRef]

84. Logan, J. Using a Spreadsheet to Model Rain Barrel Efficiency and Cost Benefit for Homeowners. HortTechnology 2014, 24, 156-158. [CrossRef]

85. Robertson, J.; Fletcher, T.; Danger, A.; Szota, C. Identifying critical inundation thresholds to maintain vegetation cover in stormwater treatment wetlands. Ecol. Eng. 2018, 116, 80-86. [CrossRef]

86. Marshall, A.M.; Link, T.E.; Flerchinger, G.N.; Nicolsky, D.J.; Lucash, M.S. Ecohydrological modelling in a deciduous boreal forest: Model evaluation for application in non-stationary climates. Hydrol. Process. 2021, 35, e14251. [CrossRef]

87. Cristiano, E.; Deidda, R.; Viola, F. EHSMu: A New Ecohydrological Streamflow Model to Estimate Runoff in Urban Areas. Water Resour. Manag. 2020, 34, 4865-4879. [CrossRef]

88. Silva, L.C.R.; Lambers, H. Soil-plant-atmosphere interactions: Structure, function, and predictive scaling for climate change mitigation. Plant Soil 2021, 461, 5-27. [CrossRef]

89. Yu, Q.; Xu, S.H.; Wang, J.; Lee, X.H. Influence of leaf water potential on diurnal changes in CO2 and water vapour fluxes. Boundary-Layer Meteorol. 2007, 124, 161-181. [CrossRef]

90. Li, X.; Zhang, L.; Zheng, Y.; Yang, D.; Wu, F.; Tian, Y.; Han, F.; Gao, B.; Li, H.; Zhang, Y. Novel hybrid coupling of ecohydrology and socioeconomy at river basin scale: A watershed system model for the Heihe River basin. Environ. Model. Softw. 2021, 141, 105058. [CrossRef]

91. Dai, Y.; Zeng, X.; Dickinson, R.E.; Baker, I.; Bonan, G.B.; Bosilovich, M.G.; Denning, A.S.; Dirmeyer, P.A.; Houser, P.R.; Niu, G.; et al. The Common Land Model. Bull. Am. Meteorol. Soc. 2003, 84, 1013-1024. [CrossRef]

92. van Dam, J.; Feddes, R. Numerical simulation of infiltration, evaporation and shallow groundwater levels with the Richards equation. J. Hydrol. 2000, 233, 72-85. [CrossRef]

93. Farquhar, G.D.; Von Caemmerer, S.; Berry, J.A. A biochemical model of photosynthetic $\mathrm{CO}_{2}$ assimilation in leaves of $\mathrm{C} 3$ species. Planta 1980, 149, 78-90. [CrossRef]

94. Collatz, G.; Ribas-Carbo, M.; Berry, J.A. Coupled Photosynthesis-Stomatal Conductance Model for Leaves of C4 Plants. Aust. J. Plant Biol. 1992, 19, 519-538. [CrossRef]

95. Xia, J.; Zhang, Y.Y.; Mu, X.M.; Zuo, Q.T.; Zhou, Y.J.; Zhao, G.J. A review of the ecohydrology discipline: Progress, challenges, and future directions in China. J. Geogr. Sci. 2021, 31, 1085-1101. [CrossRef]

96. McMillan, H.K. A review of hydrologic signatures and their applications. Wiley Interdiscip. Rev. Water 2021, 8, e1499. [CrossRef]

97. Renard, B.; Kavetski, D.; Kuczera, G.; Thyer, M.; Franks, S.W. Understanding predictive uncertainty in hydrologic modeling: The challenge of identifying input and structural errors. Water Resour. Res. 2010, 46, 05521. [CrossRef]

98. Gao, Y.; Yu, G.R. Biogeochemical cycle and its hydrological coupling processes and associative controlling mechanism in a watershed. Acta Geogr. Sin. 2018, 73, 1381-1393. [CrossRef]

99. Passeport, E.; Vidon, P.; Forshay, K.J.; Harris, L.; Kaushal, S.S.; Kellogg, D.Q.; Lazar, J.; Mayer, P.M.; Stander, E.K. Ecological Engineering Practices for the Reduction of Excess Nitrogen in Human-Influenced Landscapes: A Guide for Watershed Managers. Environ. Manag. 2013, 51, 392-413. [CrossRef]

100. Dagenais, D.; Thomas, I.; Paquette, S. Siting green stormwater infrastructure in a neighbourhood to maximise secondary benefits: Lessons learned from a pilot project. Landsc. Res. 2017, 42, 195-210. [CrossRef]

101. Taylor, J.; Hanumappa, M.; Miller, L.; Shane, B.; Richardson, M. Facilitating Multifunctional Green Infrastructure Planning in Washington, DC through a Tableau Interface. Sustainability 2021, 13, 8390. [CrossRef]

102. Martin-Mikle, C.J.; de Beurs, K.M.; Julian, J.P.; Mayer, P.M. Identifying priority sites for low impact development (LID) in a mixed-use watershed. Landsc. Urban Plan. 2015, 140, 29-41. [CrossRef]

103. Li, L.; Uyttenhove, P.; Van Eetvelde, V. Planning green infrastructure to mitigate urban surface water flooding risk-A methodology to identify priority areas applied in the city of Ghent. Landsc. Urban Plan. 2020, 194, 103703. [CrossRef]

104. Langemeyer, J.; Wedgwood, D.; McPhearson, T.; Baró, F.; Madsen, A.L.; Barton, D.N. Creating urban green infrastructure where it is needed-A spatial ecosystem service-based decision analysis of green roofs in Barcelona. Sci. Total Environ. 2020, 707, 135487. [CrossRef]

105. Song, J.Y.; Chung, E.-S. A Multi-Criteria Decision Analysis System for Prioritizing Sites and Types of Low Impact Development Practices: Case of Korea. Water 2017, 9, 291. [CrossRef]

106. Foomani, M.S.; Malekmohammadi, B. Site selection of sustainable urban drainage systems using fuzzy logic and multi-criteria decision-making. Water Environ. J. 2020, 34, 584-599. [CrossRef]

107. Steiner, F.; Brooks, K. Ecological planning: A review. Environ. Manag. 1981, 5, 495-505. [CrossRef]

108. Holling, C.S. Resilience and Stability of Ecological Systems. Annu. Rev. Ecol. Syst. 1973, 4, 1-23. [CrossRef]

109. Carpenter, S.; Walker, B.; Anderies, J.M.; Abel, N. From Metaphor to Measurement: Resilience of What to What? Ecosystems 2001, 4, 765-781. [CrossRef]

110. Brand, F.S.; Jax, K. Focusing the Meaning(s) of Resilience: Resilience as a Descriptive Concept and a Boundary Object. Ecol. Soc. 2007, 12, 23. [CrossRef]

111. Fraccascia, L.; Giannoccaro, I.; Albino, V. Resilience of Complex Systems: State of the Art and Directions for Future Research. Complexity 2018, 2018, 3421529. [CrossRef] 
112. Scheffer, M.; Carpenter, S.; Foley, J.A.; Folke, C.; Walker, B.R. Catastrophic shifts in ecosystems. Nature 2001, 413, 591-596. [CrossRef]

113. Ahern, J. Urban landscape sustainability and resilience: The promise and challenges of integrating ecology with urban planning and design. Landsc. Ecol. 2012, 28, 1203-1212. [CrossRef]

114. Fu, Y.J.; Shi, X.Y.; He, J.; Yuan, Y.; Qu, L.L. Identification and optimization strategy of county ecological security pattern: A case study in the Loess Plateau, China. Ecol. Indic. 2020, 112, 106030. [CrossRef]

115. Burton, C.G. A Validation of Metrics for Community Resilience to Natural Hazards and Disasters Using the Recovery from Hurricane Katrina as a Case Study. Ann. Assoc. Am. Geogr. 2015, 105, 67-86. [CrossRef]

116. Liu, Z.M.; Xiu, C.L.; Song, W. Landscape-Based Assessment of Urban Resilience and Its Evolution: A Case Study of the Central City of Shenyang. Sustainability 2019, 11, 2964. [CrossRef] 